\title{
Early mortality in EURODIAB population-based cohorts of type 1 diabetes diagnosed in childhood since 1989
}

\author{
C. C. Patterson • G. Dahlquist • V. Harjutsalo • \\ G. Joner • R. G. Feltbower • J. Svensson • E. Schober • \\ E. Gyürüs • C. Castell • B. Urbonaité • J. Rosenbauer • \\ V. Iotova $\cdot$ A. V. Thorsson $\cdot$ G. Soltész
}

Received: 2 June 2007 / Accepted: 7 August 2007 / Published online: 28 September 2007

(C) Springer-Verlag 2007

\begin{abstract}
Aims/hypothesis The aims of this study were to provide a contemporary picture of mortality and causes of death in Europe following a diagnosis of type 1 diabetes made before the 15 th birthday, and to examine excess mortality by country for possible links to incidence level or national prosperity. Methods Thirteen population-based EURODIAB registers in 12 countries followed-up 28,887 children diagnosed
\end{abstract}

Electronic supplementary material The online version of this article (doi:10.1007/s00125-007-0824-8) contains supplementary material, which is available to authorised users.

C. C. Patterson $(\bowtie)$

Department of Epidemiology and Public Health,

Queen's University Belfast,

Grosvenor Road,

Belfast BT12 6BJ, UK

e-mail: c.patterson@qub.ac.uk

G. Dahlquist

Department of Clinical Sciences, Paediatrics,

University of Umea,

Umea, Sweden

V. Harjutsalo

Department of Epidemiology and Health Promotion,

National Public Health Institute,

Helsinki, Finland

G. Joner

Department of Paediatrics, Ullevål University Hospital,

Oslo, Norway

R. G. Feltbower

Paediatric Epidemiology Group, University of Leeds,

Leeds, UK

\section{J. Svensson}

Paediatric Department, Glostrup Hospital,

Glostrup, Denmark since 1989, either by record linkage to population registers or through contact with doctors providing care.

Results There were 141 deaths in the cohort during 219,061 person-years of follow-up compared with 69.1 deaths expected from national mortality rates, a standardised mortality ratio (SMR) of 2.0 (95\% CI 1.7-2.4). The SMR varied from 0 to 4.7 between countries, but showed little relationship with the country's incidence rate or gross domestic product (US\$ per capita). The SMR did not change significantly with attained age, calendar period or

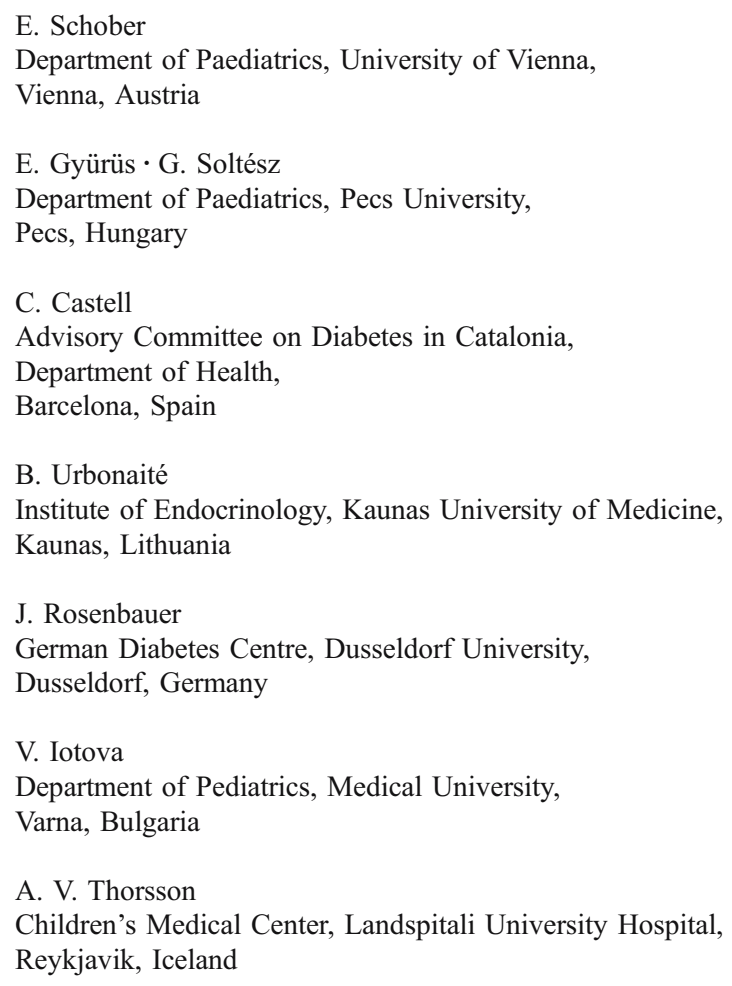


time since diagnosis. The female SMR $(2.7 ; 95 \%$ CI $2.0-$ $3.5)$ was greater than the male SMR $(1.8 ; 95 \%$ CI 1.4-2.2), although absolute numbers of excess deaths were similar in the two sexes. One-third of deaths were classified as directly attributable to diabetes (many with mention of ketoacidosis) and half were unrelated to diabetes. There was a non-significant excess of accidental/violent deaths (48 observed vs 40.7 expected; SMR 1.2; 95\% CI 0.9-1.6) but little excess in suicides (11 observed, 10.2 expected; SMR 1.1; 95\% CI 0.5-1.9).

Conclusions/interpretation Before the onset of late complications, significant excess mortality existed following the diagnosis of type 1 diabetes in childhood, even in recent years. Variation between countries in this excess could not be explained.

Keywords Cause of death · Cohort · Mortality . Standardised mortality ratio $\cdot$ Type 1 diabetes

\section{Abbreviations}

SMR standardised mortality ratio

\section{Introduction}

Although many studies have described mortality follow-up of population-based cohorts of children with type 1 diabetes, few studies have compared results from different countries. One involving Japan, Israel, Finland and Pennsylvania, USA [1], and another from Finland, Estonia and Lithuania [2] showed large variations between countries in mortality relative to that expected from national rates. The aims of the present study were: (1) to provide a contemporary picture of mortality in childhood-onset type 1 diabetes in Europe in the years after diagnosis but before the onset of cardiovascular and renal complications; (2) to present each country's mortality relative to that expected from national rates; (3) to examine excess mortality by age, sex, calendar period and time since diagnosis; and (4) to assess possible links between a country's excess mortality and its incidence level or a measure of its national prosperity.

\section{Methods}

The case inclusion criterion was that used for the EURODIAB registers [3] (new diagnosis of type 1 [insulindependent] diabetes mellitus among children aged under 15 years). Four centres (Denmark, Finland, Norway and Sweden) extended coverage of their EURODIAB cohorts to include national data for cases diagnosed since 1989. Small numbers of deaths at onset were recorded in a number of centres, but since the completeness of ascertainment of such deaths is uncertain and could vary between countries, onset deaths are not considered in this report.

Most centres obtained follow-up passively by linking the records of diabetic children to some form of official population register. Four centres (Bulgaria, Lithuania, Germany and Iceland) actively followed-up patients by tracing them through clinics or family doctors. These centres were urged to use multiple sources of ascertainment to obtain as complete a follow-up as possible, since deaths among untraced children could easily introduce bias. Record linkage follow-up ended on the date at which linkage with the population register took place, allowing for some delay in the updating of deaths on the population register, if appropriate. Individual follow-up ended on the date at which each patient's vital status (living or dead) was determined.

As much information as possible about each death was obtained (date, place, circumstances, recent medical history, autopsy report, hospital notes, registered causes of death, and underlying cause), but the amount of information available varied considerably from centre to centre. All causes of death were as coded or translated to the WHO International Classification of Diseases revision 10, the revision in use for the later part of the follow-up period. A panel of study participants used available information to classify deaths into one of four categories: (1) diabetesrelated; (2) uncertain relationship to diabetes; (3) unrelated to diabetes; and (4) unknown/insufficient information.

For nine deaths the information on the cause was sufficient to identify the disease as not being type 1 diabetes but diabetes secondary to another cause, and these deaths were excluded from the study.

Observed numbers of deaths $(\mathrm{O})$ in each cohort were compared with national mortality rates [4] using personyears at risk analysis. This involved the calculation of expected numbers of deaths (E) in the cohort given the background population mortality rates and taking account of each child's sex, age (grouped as 0-4 years, 5-9 years, 10-14 years, 15-19 years, 20+ years), and calendar period (1989-1993, 1994-1998 and 1999-) during follow-up. Standardised mortality ratios $(\mathrm{SMR}=\mathrm{O} / \mathrm{E})$ were obtained and $95 \%$ confidence limits derived using the Poisson distribution. Poisson regression [5] was used to investigate associations between a country's SMR and its incidence rate in 1989-1998 [6] and between a country's SMR and its gross domestic product (US\$ per capita) in 1994 [7]. Poisson regression was also used to compare SMRs by agegroup, calendar period, time since diagnosis and sex whilst stratifying by centre. 
Table 1 Summary of mortality follow-up results in 13 EURODIAB centres ordered by increasing incidence rate

\begin{tabular}{|c|c|c|c|c|c|c|c|c|}
\hline Centre & Cases & Registration & End of follow-up & $\begin{array}{l}\text { Lost to } \\
\text { follow-up }\end{array}$ & Person-years & $\begin{array}{l}\text { Observed } \\
\text { deaths }(\mathrm{O})\end{array}$ & $\begin{array}{l}\text { Expected } \\
\text { deaths (E) }\end{array}$ & $\begin{array}{l}\text { SMR (O/E) } \\
(95 \% \text { CI })\end{array}$ \\
\hline Lithuania & 1,006 & 1989-2003 & Jan 2004 to Feb 2005 & $11^{\mathrm{a}}$ & 7,568 & 15 & 5.2 & $2.9(1.6-4.7)$ \\
\hline Bulgaria (Eastern) & 443 & 1989-1999 & Mar 2004 & 8 & 4,069 & 10 & 2.1 & $4.7(2.3-8.7)$ \\
\hline Hungary (ex. Budapest) & 1,968 & 1989-2002 & Dec 2002 & 9 & 13,341 & 5 & 4.5 & $1.1(0.4-2.6)$ \\
\hline Austria & 1,989 & 1989-2002 & Dec 2003 & 0 & 14,744 & 6 & 4.9 & $1.2(0.5-2.6)$ \\
\hline Spain (Catalonia) & 1,809 & 1989-2002 & Dec 2005 & 0 & 18,736 & 3 & 7.1 & $0.4(0.1-1.2)$ \\
\hline Germany (Dusseldorf) & 757 & 1989-2001 & Sep 2002 to Sep 2005 & 102 & 5,027 & 4 & 1.4 & $2.8(0.8-7.2)$ \\
\hline Iceland & 151 & 1989-2004 & Dec 2005 & 0 & 1,311 & 0 & 0.5 & $0.0(0.0-6.9)$ \\
\hline Denmark & 2,285 & 1989-2002 & Dec 2002 & 27 & 13,100 & 10 & 3.3 & $3.0(1.5-5.6)$ \\
\hline UK (Leeds) & 2,248 & 1989-2004 & Dec 2005 & 1 & 18,567 & 19 & 5.3 & $4.2(2.2-5.6)$ \\
\hline Norway & 3,130 & 1989-2003 & Dec 2005 & $22^{\mathrm{a}}$ & 27,673 & 19 & 9.5 & $2.0(1.2-3.1)$ \\
\hline UK (Northern Ireland) & 1,310 & 1989-2002 & Dec 2003 & $53^{\mathrm{a}}$ & 9,453 & 9 & 3.2 & $2.9(1.3-5.4)$ \\
\hline Sweden & 7,095 & 1989-2002 & Dec 2002 & 0 & 45,160 & 14 & 9.7 & $1.4(0.8-2.4)$ \\
\hline Finland & 4,696 & $1989-2000$ & Dec 2003 & 0 & 40,312 & 27 & 12.4 & $2.3(1.4-3.2)$ \\
\hline Total & 28,887 & & & & 219,061 & 141 & 69.1 & $2.0(1.7-2.4)$ \\
\hline
\end{tabular}

${ }^{\text {a }}$ Migrants

\section{Results}

Thirteen EURODIAB centres participated in the study, following up 28,887 children diagnosed since 1989 for an average of 7.6 years (Table 1). There were 141 deaths during the 219,061 person-years of follow up $(0.64$ deaths per 1,000 person-years) compared with 69.1 deaths expected from national mortality rates. The SMR was 2.0 and varied from 0 to 4.7 between centres. Poisson regression analysis confirmed that there was statistically significant heterogeneity in SMR between centres $\left(\chi^{2}=36.7, d f=12 ; p=0.0002\right)$. However, neither incidence rate $\left(\chi^{2}=0.02, d f=1 ; p=0.89\right)$ nor gross domestic product $\left(\chi^{2}=0.48, d f=1 ; p=0.49\right)$ were able to explain this heterogeneity (Electronic supplementary material Fig. 1).

Findings obtained by aggregating results over centres are presented in Table 2. The SMR was not found to differ significantly by attained age, calendar period or time since diagnosis. However, there was evidence that the SMR was higher in females than in males $\left(\chi^{2}=5.68, d f=1 ; p=0.02\right)$.

Sufficient information about the causes of death was available to classify 134 of the 141 deaths. Of these, 47 (35\%) were assessed as being directly attributable to diabetes, including 27 with mention of diabetic ketoacidosis; $71(53 \%)$ were assessed as unrelated to diabetes; and for the remaining $16(12 \%)$ the role played by diabetes was uncertain. Five deaths were ascribed directly to hypoglycaemia. In seven deaths the patient was found dead in bed with no obvious cause, but an autopsy was not always performed and only three fulfilled strict criteria for the socalled dead-in-bed syndrome [8]. The number of deaths from accidents and violence, including suicides, was only marginally more than the number expected from national rates (48 observed vs 40.7 expected; SMR 1.2; $95 \%$ CI $0.9-1.6)$. The number of deaths from suicide was similar to that expected from national rates (11 observed vs 10.2 expected; SMR 1.1; 95\% CI 0.5-1.9).

\section{Discussion}

Our study demonstrates that significant excess mortality persists in European countries in the years following the diagnosis of type 1 diabetes in childhood but before the onset of late complications. Variation between countries is

Table 2 Follow-up results aggregated over 13 EURODIAB centres

\begin{tabular}{lcccc}
\hline & $\begin{array}{l}\text { Person-years } \\
\text { (thousands) }\end{array}$ & $\begin{array}{l}\text { Observed } \\
\text { deaths }(\mathrm{O})\end{array}$ & $\begin{array}{l}\text { Expected } \\
\text { deaths }(\mathrm{E})\end{array}$ & $\begin{array}{l}\mathrm{SMR}=\mathrm{O} / \mathrm{E} \\
(95 \% \mathrm{CI})\end{array}$ \\
\hline $\begin{array}{l}\text { Attained age (years) } \\
0-4\end{array}$ & 11.6 & 5 & 3.2 & $1.6(0.5-3.6)$ \\
$5-9$ & 46.0 & 14 & 6.7 & $2.1(1.1-3.5)$ \\
$10-14$ & 76.0 & 27 & 12.1 & $2.2(1.5-3.2)$ \\
$15-19$ & 59.1 & 56 & 28.4 & $2.0(1.5-2.6)$ \\
$20+$ & 26.5 & 39 & 18.7 & $2.1(1.5-2.9)$ \\
Calendar period & & & & \\
$1989-1993$ & 21.7 & 13 & 5.8 & $2.2(1.2-3.8)$ \\
$1994-1998$ & 70.2 & 34 & 19.4 & $1.8(1.2-2.5)$ \\
$1999-$ & 127.2 & 94 & 43.9 & $2.1(1.7-2.6)$ \\
Time since diagnosis (years) & & & \\
$0-4$ & 124.3 & 55 & 28.8 & $1.9(1.4-2.5)$ \\
$5-9$ & 70.7 & 56 & 26.6 & $2.1(1.6-2.7)$ \\
$10+$ & 24.1 & 30 & 13.8 & $2.2(1.5-3.1)$ \\
Sex & & & & \\
Male & 114.9 & 86 & 48.8 & $1.8(1.4-2.2)$ \\
Female & 104.2 & 55 & 20.4 & $2.7(2.0-3.5)$ \\
\hline
\end{tabular}


evident in this excess mortality, but our results do not suggest that it can be explained by a country's incidence rate or gross domestic product.

The use of geographically based registers with high levels of ascertainment should ensure the representativeness of the study cohorts, but we cannot be certain that the different approaches used by the various centres have not resulted in follow-up of varying quality and completeness. Despite the large overall number in the cohorts, the low rates of mortality result in relatively few deaths and may limit the power of our analysis to identify determinants of the country-to-country differences in SMR. Although we did find a significant excess in SMR among women compared with men ( 2.7 vs 1.8 ), it is worth remarking that, in absolute terms, the numbers of excess deaths in men (37.2) and women (34.6) were similar.

The rather limited and variable amount of information available about deaths in the different countries made detailed analysis of causes difficult. We chose a simple four-category classification with a consensus panel review of the less straightforward cases. The number of deaths assessed as being unrelated to diabetes (71) corresponds closely with the number of deaths expected in the cohorts from national mortality rates (69.1). Most of the excess of deaths were directly attributable to diabetes, and in the majority of such deaths there was mention of diabetic ketoacidosis. The publication of a consensus statement is a welcome step towards reducing the number of such deaths in the future [9]. Despite the difficulty in establishing low blood glucose levels post mortem, a few deaths could be ascribed to hypoglycaemia. In addition, some deaths were compatible with the dead-in-bed syndrome, which is thought to be caused by hypoglycaemia-induced cardiac arrhythmia [8].

In the words of a recent editorial, the harvest of sorrow goes on [10]. Before the onset of late complications, significant excess mortality following the diagnosis of type 1 diabetes in childhood still occurs in most European countries. Variation among countries in this excess mortality was not explained by how common the disease was in the country or the country's wealth.

Acknowledgements The authors acknowledge the following assistance, support and cooperation: the Austrian Diabetes Incidence Study Group and T. Waldhoer (Center of Public Health, Medical University of Vienna, Vienna, Austria); W. Mladenov, V. Tzaneva, R. Savova and K. Koprivarova (East and West Bulgaria Childhood Diabetes Registries); J. Tuomilehto and C. Sarti (National Public Health Institute, Helsinki, Finland); G. Giani and U. Wendel (German Diabetes Centre and Children's Hospital, Dusseldorf University, Dusseldorf, Germany); the Hungarian Childhood Type 1 Diabetes Epidemiology Group; the Catalan Type 1 Diabetes and Mortality Registers; the Swedish Childhood Diabetes Study Group and National Board of Health and Welfare; the UK Office of National Statistics; P. McKinney, J. Bodansky and C. Stephenson (Yorkshire Register of Diabetes); and the Northern Ireland Childhood Diabetes Study Group and Central Services Agency. Funding for the Swedish register was provided by Vasterbotten County Council and the Swedish Research Council and funding for the Yorkshire register was provided by the Department of Health, UK.

Duality of interest The authors declare that there is no duality of interest associated with this manuscript.

\section{References}

1. DERI Mortality Study Group (1995) International analysis of insulin-dependent diabetes mellitus mortality: a preventable mortality perspective. Am J Epidemiol 142:612-618

2. Podar T, Solntsev A, Reunanen A et al (2000) Mortality in patients with childhood-onset type 1 diabetes in Finland, Estonia, and Lithuania. Follow-up of nationwide cohorts. Diabetes Care 23:290-294

3. Green A, Gale EAM, Patterson CC (1992) Incidence of childhoodonset insulin-dependent diabetes mellitus: the EURODIAB ACE study. Lancet 339:905-909

4. World Health Organization (2007) WHO mortality database. http:// www.who.int/whosis/mort/en/index.html. Cited 14 August 2007

5. Berry G (1983) The analysis of mortality by the subject-years method. Biometrics 39:173-184

6. Green A, Patterson CC (2001) Trends in the incidence of childhood-onset diabetes in Europe 1989-1998. Diabetologia 44 (Suppl 3):B3-B8

7. Patterson CC, Dahlquist G, Soltesz G, Green A, EURODIAB ACE Study Group (2001) Is childhood-onset type 1 diabetes a wealth-related disease? An ecological analysis of European incidence rates. Diabetologia 44(Suppl 3):B9-B16

8. Heller SR (2003) Hypoglycemia and diabetes. In: Pickup JC, Williams G (eds) Textbook of diabetes, vol 1, 3rd edn. Blackwell Science, Malden, pp 33.1-33.3

9. Wolfsdorf J, Craig MA, Daneman D et al (2007) Diabetic ketoacidosis-ISPAD clinical practice consensus guidelines 2006-2007. Pediatr Diabetes 8:28-43

10. Gale EA (2005) Type 1 diabetes in the young: the harvest of sorrow goes on. Diabetologia 48:1435-1438 